\title{
Experimental validation of concentration profiles in an HCCI engine, modelled by a multi-component kinetic mechanism: outline for auto- ignition and emission control
}

\author{
Hatim Machrafi ${ }^{1,2 *}$ \\ ${ }^{1}$ UPMC Université Paris 06, Ecole Nationale Supérieure de Chimie de Paris, 11, rue de Pierre et Marie Curie, \\ 75005 Paris, France \\ ${ }^{2}$ Université de Liège, Thermodynamique des Phénomènes Irréversibles, 17, Allée du Six-Août, 4000, Liège, \\ Belgium \\ Tel.: +33144276718 Fax: +33143265813 \\ E-mail: hatim-machrafi@enscp.fr
}

\begin{abstract}
In order to contribute to the auto-ignition and emission control for Homogeneous Charge Compression Ignition (HCCI), a kinetic multi-component mechanism, containing 62 reactions and 49 species for mixtures of n-heptane, iso-octane and toluene is validated in this work, comparing for the concentration profiles of the fuel, the total hydrocarbons, $\mathrm{O}_{2}, \mathrm{CO}_{2}, \mathrm{CO}$, acetaldehyde and iso-butene. These species are sampled during the combustion and quantified. For these measurements an automotive exhaust analyser, a gas chromatograph, coupled to a mass spectrometer and a flame ionisation detector are used, depending on the species to be measured. The fuel, total hydrocarbons, $\mathrm{O}_{2}, \mathrm{CO}_{2}$, iso-butene and acetaldehyde showed a satisfactory quantitative agreement between the mechanism and the experiments. Both the experiments and the modelling results showed the same formation behaviour of the different species. An example is shown of how such a validated mechanism can provide for a set of information of the behaviour of the auto-ignition process and the emission control as a function of engine parameters.
\end{abstract}


Keywords: Combustion, Reduced kinetic mechanism, HCCI auto-ignition, Experimental validation, engine gas sampling during combustion, Gas Chromatography and Mass Spectrometry

\section{Introduction}

The HCCI mode of combustion appears to be an interesting solution for the reduction of the automobile pollution. However, the control of its auto-ignition and emission are still to be fully comprehended. Such an investigation can be performed by means of kinetic modelling. In order to use a kinetic mechanism for auto-ignition control and emission control it is necessary to validate that mechanism. Generally, mechanisms for engine purposes are validated against global auto-ignition parameters. If one wants to use a mechanism for emission control as well, it should also be validated against the concentration profiles of some major and some important intermediate species during the combustion. This, since a correct prediction of the profile of species during the combustion makes a mechanism reliable for the calculation of the concentrations of several species during the combustion. Such a tool is important for the understanding of the mechanisms that cause pollution and in this way a validated mechanism can be used for the purpose to control the emissions.

Much work [1-4] has been presented, investigating auto-ignition for many compounds. A great part of these investigations [5-9] use the so-called Primary Reference Fuels (PRF) such as iso-octane and n-heptane. To account for aromatics in gasoline and especially diesel, mostly toluene is added for this purpose [10-15]. Therefore these three fuels are used for this investigation. For a better understanding of the auto-ignition process, the use of kinetic mechanisms can be an important tool, especially of a reduced form [16-19]. Performing a parametrical analysis on auto-ignition requires kinetic models of low dimensionality. In this 
way, a wide range of calculations can be made within a short period of computing time. Moreover, with the intention to understand the behaviour of the auto-ignition process, influenced by several parameters, such a kinetic mechanism can give more insight of how the parameters influence the chemical species evolution during the auto-ignition. Reduced models for hydrocarbon auto-ignition are also being applied to Computational Fluid Dynamics (CFD) codes. A reduced kinetic mechanism representing the auto-ignition of n-heptane, iso-octane and toluene, containing 62 reactions and 49 species, has been developed, numerically validated and compared to constant volume experiments in previous work [20], called the surrogate mechanism. Moreover, it has been calibrated by experiments with regard to the heat exchanges to the wall and the effect of the residual gases in an HCCI engine [21]. The impact of the estimation of the residual gas fraction and temperature appeared to be crucial and it could well be the main factor of error in comparing the experimental results with the chemical kinetic calculations of the surrogate mechanism.

The possibility of using this calibrated mechanism for the purposes of emission control in an HCCI engine can be investigated by calculating the concentration profile of important species and comparing them with experimentally measured concentrations of those same species. These experimental values should be extracted from the cylinder during the combustion at several Crank Angle Degrees. Much research has been performed, showing detailed kinetic mechanisms being compared to experimental results, concerning the profile of species as a function of time. Examples are the work of Baldwin et al. [22], Morley [23], Slagle et al. [24], Hughes et al. [25], Baulch et al. [26] and others [27-31]. Often, these mechanisms describe the oxidation or auto-ignition of one fuel and often the mechanisms are detailed. Moreover, the experimental apparatus with which the experiments are done, are often static or with a constant volume. Not many mechanisms are experimentally validated whilst describing the 
oxidation or auto-ignition in an engine. Griffiths [32] states that the fundamental, qualitative difficulty is that a kinetic scheme, which has been reduced to an extent that is both desirable and broadly acceptable for one purpose may not be at all satisfactory for another. The present problems arise largely from the omission of elementary reactions for the formation of partially oxygenated intermediates followed by their subsequent oxidation. This can have a profound effect on both the rate and the extent of the heat release through the associated enthalpy changes. Various works [32-36] shows the importance of modelling work and its validation by experimental work concerning combustion systems. Many works performed measurements of species at both the exhaust pipe and during the combustion [37-40]. Mishra et al. [41] measured concentrations of selected hydrocarbons $\left(\mathrm{CH}_{4}, \mathrm{C}_{2} \mathrm{H}_{6}, \mathrm{C}_{2} \mathrm{H}_{4}\right.$ and $\left.\mathrm{C}_{2} \mathrm{H}_{2}\right)$ have been measured in $\mathrm{CH}_{4}$ /air partially premixed flames for different primary mixture equivalence ratio and primary jet velocity using gas chromatography. To the best of the knowledge found in the literature, no substantial work is found containing strongly reduced multi-component fuel mechanisms which are experimentally validated in an HCCI engine with regard to the profile of its most important intermediate and final product species. Such mechanisms could be used for emission control of an HCCI engine.

Considering these observations, the aim of this paper can be divided in two parts. The first is to validate experimentally the reduced kinetic mechanism against experimental concentration profiles with the use of an HCCI engine $[\mathbf{2 0 , 2 1 , 4 2 ]}$. In this study, the experimental concentration profiles are extracted from [43] and reconverted from ppmC into ppmv. The reconversion is done by dividing the number of $\mathrm{ppmC}$ by the number of $\mathrm{C}$-atoms present in the component in question, obtaining the number of ppmv. The gas that is sampled from the engine cylinder is separated by a Gas Chromatograph, identified and quantified by a Mass Spectrometer and a Flame Ionisation Detector (for hydrocarbons). The species that are used 
for the validation of the surrogate mechanism by the experiments are the fuel $(60 \mathrm{vol} \% \mathrm{n}$ heptane / 40 vol\% iso-octane), the total hydrocarbons (THC), $\mathrm{CO}, \mathrm{CO}_{2}, \mathrm{O}_{2}, \mathrm{CH}_{3} \mathrm{CHO}$ and isobutene. These species cover the fuel, some major pollutants $\left(\mathrm{CO}, \mathrm{CO}_{2}\right.$ and $\left.\mathrm{THC}\right)$, cool flame intermediaries $\left(\mathrm{CH}_{3} \mathrm{CHO}, \mathrm{CO}\right)$ and species formed after the cool flame during the Negative Temperature Coefficient, NTC (iso-butene), all of which contribute eventually to the final heat release and thus the final auto-ignition. Finally, an example is presented of how such a mechanism could be used for both auto-ignition control and emission control.

\section{Experimental set-up}

Figure 1 shows the experimental set-up that is used for both the auto-ignition experiments [21] and the gas sampling experiments [43]. The fuel that is used is PRF40. More information concerning the experimental set-up of the HCCI engine can be consulted in [21]. The HCCI engine, running at $600 \mathrm{rpm}$, has a compression ratio of 10.2, a bore of $82.55 \mathrm{~mm}$, a stroke of $114.5 \mathrm{~mm}$ and a displacement volume of $612 \mathrm{~cm}^{3}$. The ratio of the connecting rod to crank radius is 4.44 . The exhaust valve opens at $140^{\circ}$ After Top Dead Center (ATDC) and closes at $15^{\circ} \mathrm{ATDC}$. The intake valve opens at $10^{\circ} \mathrm{ATDC}$ and closes at $146^{\circ} \mathrm{BTDC}$. It concerns a water-cooled mono-cylinder engine, where the inlet temperature and pressure can be regulated and measured with an error of respectively $+/-1{ }^{\circ} \mathrm{C}$ and $+/-3 \mathrm{mbar}$. The fuel/air mixture is continuously prepared in a mixture tank by controlling the air flow (+/- $2 \%)$ and the fuel flow $(+/-1 \%)$. The fuel is injected in the mixture tank by a nebulizer using a High Pressure Liquid Chromatograph (HPLC), assisted by 1.5 bar pressurized air. By controlling the fuel and air flow, the equivalence ratio can be chosen, with a confidence interval of $+/-$ 0.005. The compression ratio can be chosen by changing the position of the cylinder head (confidence interval $+/-0.5$ ). The fuel is composed by measuring the volumetric quantity (confidence interval +/- 1 vol\%) of each constituent of the fuel and mixing these together. The 
fuel/air mixture is auto-ignited by compression. The pressure in the cylinder is measured by a piezo-electric pressure sensor mounted in the cylinder head. The standard deviation of the pressure is $1.5 \%$ during the ignition. These deviations lead to a confidence interval of the ignition delays of +/- 0.5 CAD.

One of the characteristics of HCCI engines is that the combustion process proceeds in a relatively short time. The sampling duration is thus of great importance. If the sampling duration is too big, the measurements will give results that are based on several crank angle degrees. Much information would be lost. On the other side, if the duration is too small, not enough volume can be collected for the analysis. Detailed information about this sampling procedure, the sampling probe and its calibration can be found in [43]. To obtain fast response, the percussion principle as described by Zhao et al. [44] was used. The optimal sampling duration seemed then to be $3.33 \mathrm{~ms}$. This corresponds to a sampling window of 12 $\mathrm{CAD}$, with $70 \%$ of the volume being sampled within $6 \mathrm{CAD}$. It is necessary to sample from several hundreds of combustion cycles in order to collect sufficient sample volume for the gas analysis system and to get a result independent on the influence of cyclic variations in the combustion process. The concentration measurement's uncertainty of the species in question is between $4 \%$ (the heaviest species) and $22 \%$ (the lightest species), while this is $2 \%$ for CO, $\mathrm{CO}_{2}$ and $\mathrm{O}_{2}$. The sampling was operated every 10 cycles so as to minimize the effects of the sampling procedure on the combustion process. This sampling procedure involved about 20 minutes of stabilized engine running.

\section{Results and discussion}

This section presents the obtained results of the comparison of the kinetic mechanism with the experiments concerning the profile of the species mentioned in the introduction: the fuel 
PRF40, THC, $\mathrm{CO}, \mathrm{O}_{2}, \mathrm{CO}_{2}$, acetaldehyde $\left(\mathrm{CH}_{3} \mathrm{CHO}\right)$ and iso-butene $\left(\mathrm{IC}_{4} \mathrm{H}_{8}\right)$. Each result is accompanied by a pressure curve, in order to indicate the stage of the in-cylinder combustion. The experimental difficulties and development are explained in [43] and the results for the experimental concentration profiles are used from it, which are subsequently reconverted from ppmC to ppmv for this study, in order to compare the results with the kinetic mechanism. The operating conditions are: an inlet temperature of $70{ }^{\circ} \mathrm{C}$, an equivalence ratio of 0.4 , a compression ratio of 10.2 and an inlet pressure of 1 bar.

\subsection{The profile of major species during the combustion}

In this subsection, the profile of the major combustion species (the fuel, the total hydrocarbon content, $\mathrm{O}_{2}$ and $\mathrm{CO}_{2}$ ) is presented as a function of the engine's crank angle degree. Numerical results, obtained from the surrogate mechanism, are compared to the experimental results, obtained from the GCMS. Figure 2 presents this comparison for the fuel PRF40 and the total hydrocarbon content during the combustion.

Figure 2 shows that the mechanism, taking account of the experimental measuring errors, predicts quite satisfactorily the profile of the fuel degradation and that of the total hydrocarbons. The two-stage combustion (cool flame and final ignition), comprising three

steps, is nicely represented by both the mechanism and the experiments. The first step represents the consumption of the fuel and the THC, caused by the cool flame. At the second step, the consumption becomes less intensive (indicated by the arrows in figure 2), representing the NTC, which stands also for decreased reactivity. It can be seen that both the mechanism and the experiments show an interruption in the decrease of the concentrations. The final step, is where the consumption becomes more intensive, consuming the majority of the fuel and the total hydrocarbons. This is called the final ignition. Figure 2 gives another interesting observation. Both the mechanism and the experiments show that during the NTC 
(indicated by arrows), the THC concentration becomes higher than that of the fuel, while both decrease. This means that the fuel's concentration decreases faster than that of the THC, since the fuel consumption produces other hydrocarbons, which are mainly olefins, of which the concentrations increase. This makes the THC concentration decrease less than the fuel. This observation is well predicted by the mechanism.

Figure 3 presents the comparison of the numerical results with the experimental ones, concerning the profiles of oxygen and carbon dioxide. The experimental values of $\mathrm{CO}_{2}$ and $\mathrm{O}_{2}$ validate satisfactorily the numerical values of the surrogate mechanism. The two-stage combustion is made visible by the $\mathrm{O}_{2}$ concentration, not only numerically, but also the experiments show this two-step consumption of oxygen. The beginning values and the end values of $\mathrm{CO}_{2}$ and $\mathrm{O}_{2}$ correspond well within the measurement errors. The main difference appears to be that the experimental values change gradually, whilst the numerical values change abruptly at the final ignition. This is due to inhomogeneity and due to the sampling window of $12 \mathrm{CAD}$. The 0D model assumes a perfect homogeneous combustion, whilst in the reality it is possible that, for instance near the wall, the combustion takes place later than in the middle of the cylinder. The sampled gas is a mean value of what is present in the cylinder and, therefore, the measured change in the concentration is not abrupt. However, the fact that the agreement between modelling and experimental values is rather good suggests that the mixing effect only plays a minimal role, justifying the "quasi-homogeneity" character of the HCCI combustion. The effect of the mixing can be evaluated when the kinetic mechanism is implemented in a $3 \mathrm{D}$ code, though.

\subsection{The profile of intermediary minor species during the combustion}

Figure 4 presents the comparison between the mechanism and the experiments for CO. Figure 4 shows that the production and the consumption of $\mathrm{CO}$ are well predicted both qualitatively 
and quantitatively, except for the maximum value of $\mathrm{CO}$. The explanation could be that the maximum production of $\mathrm{CO}$ takes place at a short window of time. The gas sampling probe opens for a certain amount of time, during which the piston keeps moving. So the gas concentration that is measured is a mean value taken over that window of time. This window of time being larger than the time $\mathrm{CO}$ is at its maximum value, the real value cannot be measured by the experiments and the mean value is lower, as is presented in figure 4. Nonetheless, it appears that the moment at which CO's experimental value is at its maximum coincides with the moment at which this is the case for the numerical value. A small discrepancy appears for the final value of $\mathrm{CO}$. Where the mechanism predicts no $\mathrm{CO}$ at the end of the combustion, the experiments show a certain value. Due to the low temperature at the expansion stroke, which is typical for a HCCI combustion cycle, and the thermal exchanges with the wall, the reaction that converts $\mathrm{CO}$ to $\mathrm{CO}_{2}$ is quenched, leaving some $\mathrm{CO}$ in the exhaust. The mechanism does not take this into account and assumes complete combustion, converting eventually all the $\mathrm{CO}$ into $\mathrm{CO}_{2}$. Figure 8 presents a comparison of the experiments and the simulation by the surrogate mechanism of the concentrations of acetaldehyde and iso-butene.

Figure 5 shows that the experimental profile of acetaldehyde and iso-butene have the same trend as the numerical profiles. The two-stage formation of acetaldehyde and iso-butene is clearly visible, indicating the NTC by an arrow in figure 5, after which total consumption follows. These experimental trends correspond well with the numerical ones, qualitatively speaking that is. Quantitatively, the agreement is good as well, except for the maximum concentrations of both the species. It can be seen, as was the case for $\mathrm{CO}$ in figure 4 , that when the mechanism predicts a peak concentration of acetaldehyde and iso-butene, the experiments do not. The reason is the same as is explained for CO. The maximum concentration of acetaldehyde and iso-butene takes place at a relatively small time interval. 
The gas sampling probe opens for a certain amount of time, during which the piston keeps moving. So the gas concentration that is measured is a mean value taken over that window of time. This window of time being larger than the time the two species are at their maximum value, the real value cannot be measured by the experiments and the mean value is lower, as is presented in figure 5. It appears, though that the moment at which the experimental concentration values of acetaldehyde and iso-butane are at their maximum coincides with the moment at which this is the case for the numerical value. Interestingly, the mechanism predicts, as the experiments, higher concentrations of iso-butene than acetaldehyde.

\subsection{Concluding remarks}

The results have shown that the kinetic mechanism predicts well the concentration profiles of the fuel, the total hydrocarbons, $\mathrm{CO}_{2}$ and $\mathrm{O}_{2}$. The concentration profiles of the intermediary species (acetaldehyde, iso-butene, $\mathrm{CO}$ ) are predicted also well. The trends are represented correctly. However, the maximum quantitative value of these three species is underestimated. This could be caused by relatively large window in which the sampling probe opens. Knowing that the intermediary species are produced and consumed rapidly, this results into measuring a mean value instead of instantaneous values of the species' concentration. The trends, though, are overall well represented. It should be noted that other small species, such as propene and ethene, were only qualitatively well predicted by the mechanism and are therefore not presented in this paper. The quantitative values were over predicted by the mechanism. However, these species have much smaller concentrations [43] than the ones presented in this paper and are thus of little importance for the products present in the emission. Therefore, the mechanism [21] is considered validated for the use of emission control, which is elucidated in the next section. 


\section{Application of an experimentally validated reduced kinetic mechanism}

Having validated the kinetic mechanism experimentally, an example will be shown in this section, explaining how the mechanism can be used for auto-ignition and emission control. Figures 6 to 8 present respectively the indicated efficiency with the hydrocarbon emission, the $\mathrm{CO}$ emission with the $\mathrm{CO}_{2}$ emission and the indicated efficiency with the final ignition delay. These results are obtained by the kinetic mechanism for an inlet temperature of $70^{\circ} \mathrm{C}$ with " 60 vol\% n-heptane / $40 \mathrm{vol} \%$ iso-octane" as the fuel for several equivalence ratios and compression ratios. It is clear, from figure 6 , that an acceptable indicated efficiency $(30 \%)$ is attained when the equivalence ratio is higher than about 0.3 . Such an area is indicated by a gray area in figures 6 to 8 for the indicated efficiency, the emissions and the final ignition delay. It is not the objective to choose a particular equivalence ratio, but rather a range of equivalence ratios, where the indicated efficiency is as high as possible and the emissions of $\mathrm{CO}$ and the hydrocarbons as low as possible. The objective is to control the auto-ignition such that the indicated efficiency stays above $30 \%$ and the emissions do not increase. The first question that could arise is which compression-ratio-range is suitable. A certain critical compression ratio (CCR) can be defined, which is needed for a fuel to burn in an engine cylinder. Furthermore, figure 6 shows that at higher equivalence ratios and compression ratios, the sensitivity of the emissions as a function of these two parameters is less. This can be seen by the slope of the iso-values. The optimum of the compression ratio, at an equivalence ratio of at least 0.3 , is for " $60 \mathrm{vol} \% \mathrm{n}$-heptane / $40 \mathrm{vol} \%$ iso-octane" between 9 and 11.5. Figure 6 shows furthermore the competition between a high indicated efficiency and a low hydrocarbon emission. If one wants to lower the hydrocarbon emission to, for instance, 1380 ppmv, the indicated efficiency would decrease. An optimum should be found. Figure 6 is an example of how a kinetic mechanism could provide information in order to find such an 
optimum. The same optimum should be found for the $\mathrm{CO}$ and $\mathrm{CO}_{2}$ emissions. Figure 7 shows that a lower $\mathrm{CO}_{2}$ emission results globally into a higher $\mathrm{CO}$ emission. Moreover, a lower $\mathrm{CO}_{2}$ emission can be accomplished by lowering the equivalence ratio and the compression ratio, which could result into a lower engine power output. These three parameters are in competition with each other. The lower engine power output is also linked with the final ignition delay, presented in figure 8. It is thus clear that the indicated efficiency, the emissions, the ignition delay and the power output are all linked with each other. This means that auto-ignition control and emission control are also linked. The information provided in figures 6 to 8 can be used to illustrate an example of auto-ignition control and emission control in an HCCI engine. Say an HCCI engine is running at a final ignition delay of 179 $\mathrm{CAD}$ at an equivalence ratio of 0.3 and a compression ratio of 9.2. Say, in order to attain a certain acceleration, the final ignition delay should be momentarily 172 CAD. Many options are available. Two are presented with a solid (case A) and a dashed (case B) arrow in figure 8 . In case $A$ the equivalence ratio and compression ratio are set to respectively 0.39 and 9.8 . In case $\mathrm{B}$ the equivalence ratio and compression ratio are set to respectively 0.31 and 10.5 . Figure 8 shows that this corresponds with a change in the indicated efficiency from $36 \%$ to respectively $33 \%$ (case A) and $32 \%$ (case B). The same changes are indicated in figures 6 and 7. It appears that in case A, the hydrocarbon emission goes from 2000 to $1480 \mathrm{ppmv}$ and in case $\mathrm{B}$, from 2000 to $1580 \mathrm{ppmv}$. In case A, the CO emission goes from 0.45 to $0.12 \mathrm{vol} \%$ and in case $\mathrm{B}$ from 0.45 to $0.18 \mathrm{vol} \%$. In case $\mathrm{A}$, the $\mathrm{CO}_{2}$ emission goes from 3.4 to $4.5 \mathrm{vol} \%$ and in case B from 3.4 to 3.8 vol\%. Observing these results, it can be seen clearly, that the change of the equivalence ratio in case $\mathrm{A}$ in order to control the auto-ignition delay results into a higher indicated efficiency than in case B. Also, the hydrocarbon and $\mathrm{CO}$ emissions are lower in case $\mathrm{B}$. However, the $\mathrm{CO}_{2}$ emission is higher in case $\mathrm{A}$ than in case $\mathrm{B}$. This shows the outline of an emission control. It can be seen that it is complicated to satisfy all the 
objectives concerning the auto-ignition and emission control. Nonetheless, a lot can be accomplished in this way and an optimum can be found. One of the solutions is to use a kinetic mechanism for this purpose. This is the final objective of this paper and an example of a possible outline has been presented.

\section{Conclusions}

In previous work, a surrogate mechanism is composed out of 62 reactions and 49 species, representing the auto-ignition of mixtures of n-heptane, iso-octane and toluene. There, the surrogate mechanism is validated numerically in a wide range of parameters adhering to HCCI initial conditions, involving low inlet temperatures and equivalence ratios.

The kinetic mechanism is also validated experimentally against some important species' concentration profiles. The results show a satisfactory quantitative agreement between the experimental and the modelling results, for the species $\mathrm{CO}_{2}, \mathrm{O}_{2}$, the fuel and the total hydrocarbons. The agreement is also quantitatively acceptable for the species $\mathrm{CO}$, acetaldehyde and iso-butene, except for the maximum values that are higher in the case of the mechanism. The discrepancies are mainly due to the absence of aerodynamics, in the case of the modelling code, and due to the relation between the sampling procedure and the kinetics in the engine. Rapid kinetic changes are too difficult to be measured by the sampling device, due to the sampling time window that is necessary to collect enough volume. This excludes values of rapid changes in the species' concentrations, leading to the measurement of mean values and relatively slower changes in the values. Nonetheless, the overall trends of all the species, as predicted by the kinetic mechanism, correspond rather well with the experiments. Moreover, the predicted profiles of the species that are abundant in the emission, such as $\mathrm{CO}_{2}$, $\mathrm{O}_{2}$ and the total hydrocarbons, correspond quantitatively well with those obtained from the experiments. Therefore, the reduced kinetic mechanism is considered to be validated 
experimentally with respect to concentration's profiles of some important intermediary species and end products. This experimental validation has been performed in order to use the kinetic mechanism for emission control.

One of the applications of the kinetic mechanism has been shown by composing a contour map of the final ignition delays, the indicated efficiency and the emissions of hydrocarbons, $\mathrm{CO}$ and $\mathrm{CO}_{2}$ as functions of the equivalence ratio and the compression ratio, using a PRF40 fuel. An example has been presented, showing how the kinetic mechanism proposes an outline of auto-ignition control and emission control, using the equivalence ratio and compression ratio as the parameters. 


\section{References}

[1] Curran HJ, Gaffuri P, Pitz WJ, Westbrook CK. A comprehensive Modeling Study of isoOctane Oxidation. Comb. Flame 2002; 129: 253-280.

[2] Tanaka S, Ayala F, Keck JC. A reduced chemical kinetic model for HCCI combustion of primary reference fuels in a rapid compression machine. Comb. Flame 2003; 133: 467-481.

[3] Tanaka S, Ayala F, Keck JC, Heywood JB. Two-stage ignition in HCCI combustion and HCCI control by fuels and additives. Comb. Flame 2003; 132: 219-239.

[4] Griffiths JF, MacNamara JP, Sheppard CGW, Turton DA, Whitaker BJ. The relationship of knock during controlled autoignition to temperature inhomogeneities and fuel reactivity. Fuel 2002; 81: 2219-2225.

[5] Bikas G, Peters N. Brief communication: Kinetic Modelling of n-Decane Combustion and Autoignition. Comb. Flame 2001; 126: 1456-1475.

[6] Aichlmayr HT, Kittelson DB, Zachariah MR. Miniature free-piston homogeneous charge compression ignition engine-compressor concept - Part II: modeling HCCI combustion in small scales with detailed homogeneous gas phase chemical kinetics. Chem. Eng. Sc. 2002; 57: 4173-4186.

[7] Ogink R, Golovitchev V. Generalised Skeletal Reaction Mechanism For Aliphatic Hydrocarbons (From Methane To Iso-octane) For CFD Engine Modelling. First Biennial Meeting of The Scandinavian-Nordic Section of the Combustion Institute, Göteborg 2001: $151-156$.

[8] Gauthier BM, Davidson DF, Hanson RK. Shock tube determination of ignition delay times in full-blend and surrogate fuel mixtures. Comb. Flame 2004; 139: 300-311.

[9] Minetti R, Carlier M, Ribaucour M, Therssen E, Sochet LR. Comparison of oxidation and autoignition of the two primary reference fuels by rapid compression. Twenty-Sixth Symposium (International) on Combustion 1996: 747-753. 
[10] Djurisic ZM. Joshi AV, Wang H. Detailed Kinetic Modeling of Benzene and Toluene Combustion. Second Joint Meeting of the U.S. Sections of the Combustion Institute, Oakland (2001).

[11] Glassman I. Combustion. Academic Press, San Diego, 1996. p. 84.

[12] Dagaut P, Pengloan G, Ristori A. Oxidation, ignition and combustion of toluene: experimental and detailed chemical kinetic modeling. Phys. Chem. Chem. Phys. 2002; 4: $1846-1854$.

[13] Faravelli T. Kinetic Modeling of New Formulated Gasoline. International Conference ICE 97, Capri (1997).

[14] Emdee J, Brezinsky K, Glassman I. A Kinetic Model for the Oxidation of Toluene near 1200 K. J. Phys. Chem. 1992; 96: 2151-2161.

[15] Lindstedt R, Maurice L. Detailed Kinetic Modelling of Toluene Combustion. Comb. Sc. Tech. 1996; 120: 119-167.

[16] Lovas T, Nilsson D, Mauss F. Automatic reduction procedure for chemical mechanisms applied to premixed methane/air flames, Twenty-Eighth International Symposium on Combustion, 2000: 1809-1815.

[17] $\mathrm{Lu} \mathrm{T,} \mathrm{Ju} \mathrm{Y,} \mathrm{Law} \mathrm{CK.} \mathrm{Complex} \mathrm{CSP} \mathrm{for} \mathrm{Chemistry} \mathrm{Reduction} \mathrm{and} \mathrm{Analysis.} \mathrm{Comb.}$ Flame 2001; 126: 1445-1455.

[18] Maass U, Pope SB. Simplifying chemical kinetics: Intrinsic low-dimensional manifolds in composition space. Comb. Flame 1992; 88: 239-264.

[19] Warnatz J, Maass U, Dibble RW. Combustion Physical and chemical fundamentals, modeling and simulation, experiments, pollutant formation. Springer-Verlag, New York, 2000 . 
[20] Machrafi H, Cavadias S, Amouroux J. The development and experimental validation of a reduced ternary kinetic mechanism for the auto-ignition at HCCI conditions, proposing a global reaction path for ternary gasoline surrogates, 2009, Fuel Proc. Tech. 90(2), 247-263.

[21] Machrafi H. Experimental validation of a kinetic multi-component mechanism in a wide HCCI engine operating range for mixtures of n-heptane, iso-octane and toluene: Influence of EGR parameters, 2008, Energy Conv. Manag. 49 (11); 2956-2965.

[22] Baldwin RR, Lodhi ZH, Stothard N, Walker RW. The Oxidation Chemistry of Allyl Radicals and Related 'Stable’ Radicals, Proc. Combust. Inst. 1990; 23: 123-130.

[23] Morley C. Chemical kinetic modeling and sensitivity analysis for boron assisted hydrocarbon combustion, Proc. Combust. Inst. 1988; 22: 911-918.

[24] Slagle IR, Benscura A, Xing S-B, Gutman D. Kinetics and thermochemistry of the oxidation of unsaturated radicals: $\mathrm{C}_{4} \mathrm{H}_{5}+\mathrm{O}_{2}$, Proc. Combust. Inst. 1992; 24: 653-660.

[25] Hughes KJ, Halford-Maw PA, Lightfoot PD, Griffiths JF, Turanyi T, Pilling MJ. Direct measurements of neopentyl peroxy-hydroperoxy radical isomerisation over the temperature ranges 660 - $750 \mathrm{~K}$, Proc. Combust. Inst. 1992; 24: 645-652.

[26] Baulch DL, Griffiths JF, Richter R. Measurements of reactant temperature and freeradical concentrations during the oscillatory combustion of hydrogen and carbon monoxide in a CSTR, Chem. Eng. Sci. 1991; 46: 2315-2322.

[27] Okasha F. Modeling of liquid fuel combustion in fluidized bed, Fuel 2007; 86: 22412253.

[28] Stauch R, Maas U. The ignition of methanol droplets in a laminar convective environment, Combust. Flame 2007; 153: 45-57.

[29] Sua H, Vikhanskya A, Mosbacha S, Krafta M, Bhaveb A, Kimc K, Kobayashic T Mauss F. A computational study of an HCCI engine with direct injection during gas exchange, Combust. Flame 2006; 147: 118-132. 
[30] Ribaucour M, Lemaire O, Minetti R. Low-temperature oxidation and autoignition of cyclohexene: A modeling study, Proc. Combust. Inst. 2002; 29: 1303-1310.

[31] Cancès J, Commandré JM, Salvador S, Dagaut P. NO reduction capacity of four major solid fuels in reburning conditions - Experiments and modeling, Fuel 2008; 87: 274-289.

[32] Griffiths JF. Reduced kinetic models and their application to practical combustion systems, Prog. Energ. Combust. Sc.1995; 21: 25-107.

[33] Zheng J, Yang W, Miller DL. Cernansky N.P, A Skeletal Chemical Kinetic Model for the HCCI Combustion Process, SAE 2002; 2002-01-0423.

[34] Chen R, Milovanovic N. A computational study into the effect of exhaust gas recycling on homogeneous charge compression ignition combustion in internal combustion engines fuelled with methane, Intern. J. Therm. Sc. 2002; 41: 805-813.

[35] Li H, Miller DL, Cernansky NP. A Study on the Application of a Reduced Chemical Reaction Model to Motored Engines for Heat Release Prediction, SAE 1992; 922328.

[36] Ferguson R, Green RM, Lucht RP. Unburned gas temperatures in an internal combustion engine. II: Heat release computations, Comb. Sci. Technol. 1987; 55: 63-81

[37] Whitehouse ND, Clough E, Roberts PS. Investigating diesel engine combustion by means of a timed sampling valve, SAE 1977; 770409.

[38] Minetti R, Carlier M, Ribaucour M, Thersssen E, Sochet LR. A rapid Compression Machine Investigation of Oxidation and Auto-Ignition of n-heptane: Measurements and Modeling, Combust. Flame 1995; 102: 298-309.

[39] Ogawa H, Chenyu L, Miyamoto N, Tosaka S, Fujiwara Y. Combustion Mechanism Analysis with In-chamber Gas Composition Measurements in a Premixed Lean Compression Ignition Engine, International Symposium Comodia 1998; 4: 167-172. 
[40] Fujimoto HG, Senda J, Ito T, Asao S, Higashi K. Characteristics of Intermediate Products Generated During Diesel Combustion by Means of Total Gas Sampling, Powertrain \& Fluid Systems, SAE 2004; 2004-01-2923.

[41] Mishra TK, Datta A, Mukhopadhyay A. Concentration measurements of selected hydrocarbons in methane/air partially premixed flames using gas chromatography, Intern. J. Therm. Sc. 2005; 44: 1078-1089.

[42] Machrafi H, Cavadias S. Three-stage autoignition of gasoline in an HCCI engine: An experimental and chemical kinetic modeling investigation, Combust. Flame 2008; 155 (4), $557-570$.

[43] Nowak L, Guibert P, Cavadias S, Dupré S, Momique JC. Methodology development of a time-resolved in-cylinder fuel oxidation analysis: Homogeneous charge compression ignition combustion study application, Combust. Flame 2008; 154 (3), 462-472.

[44] Zhao H, Lowry G, Ladommatos N. Time-Resolved Measurements and Analysis of InCylinder Gases and Particulates in Compression-Ignition Engines, SAE 1996; 961168. 


\section{Figure captions}

Figure 1: Schematic representation of the experimental set-up [21,43]

Figure 2: Concentration profile during the combustion of the fuel and the total hydrocarbons; experimental [43] by points and numerical by lines; inlet temperature of $70{ }^{\circ} \mathrm{C}$, equivalence ratio of 0.4 , compression ratio of 10.2 and PRF40 as the fuel

Figure 3: Concentration profile during the combustion of $\mathrm{CO}_{2}$ and $\mathrm{O}_{2}$; experimental [43] by points and numerical by lines; inlet temperature of $70{ }^{\circ} \mathrm{C}$, equivalence ratio of 0.4 , compression ratio of 10.2 and PRF40 as the fuel

Figure 4: Concentration profile during the combustion of $\mathrm{CO}$; experimental [43] by points and numerical by lines; inlet temperature of $70{ }^{\circ} \mathrm{C}$, equivalence ratio of 0.4 , compression ratio of 10.2 and PRF40 as the fuel

Figure 5: Concentration profile during the combustion of acetaldehyde and iso-butene; experimental [43] by points and numerical by lines; inlet temperature of $70{ }^{\circ} \mathrm{C}$, equivalence ratio of 0.4 , compression ratio of 10.2 and PRF40 as the fuel

Figure 6: Iso-indicated efficiencies (left in \%), hydrocarbon emissions (right in ppmv) as a function of the equivalence ratio and the compression ratio, for an inlet temperature of $70^{\circ} \mathrm{C}$ with " 60 vol\% n-heptane / 40 vol\% iso-octane" as the fuel

Figure 7: $\mathrm{CO}$ emissions (left in vol\%) and $\mathrm{CO}_{2}$ emissions (right in vol\%) as a function of the equivalence ratio and the compression ratio, for an inlet temperature of $70^{\circ} \mathrm{C}$ with " $60 \mathrm{vol} \%$ n-heptane / 40 vol\% iso-octane" as the fuel

Figure 8: Iso-indicated efficiencies (left in \%) and the final ignition delay (right in CAD) as a function of the equivalence ratio and the compression ratio, for an inlet temperature of $70^{\circ} \mathrm{C}$ with "60 vol\% n-heptane / 40 vol\% iso-octane" as the fuel 
Figures

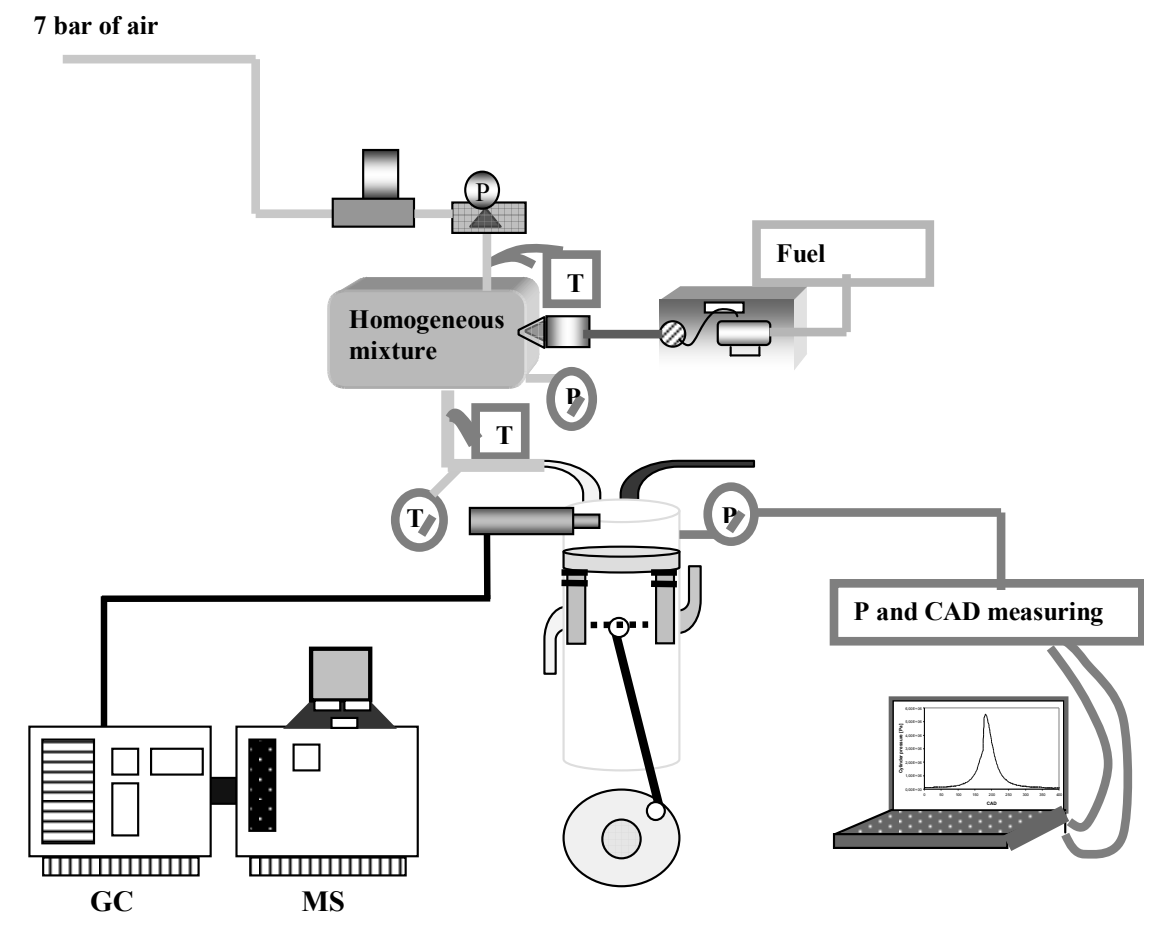

Figure 1: Schematic representation of the experimental set-up [21,43] 


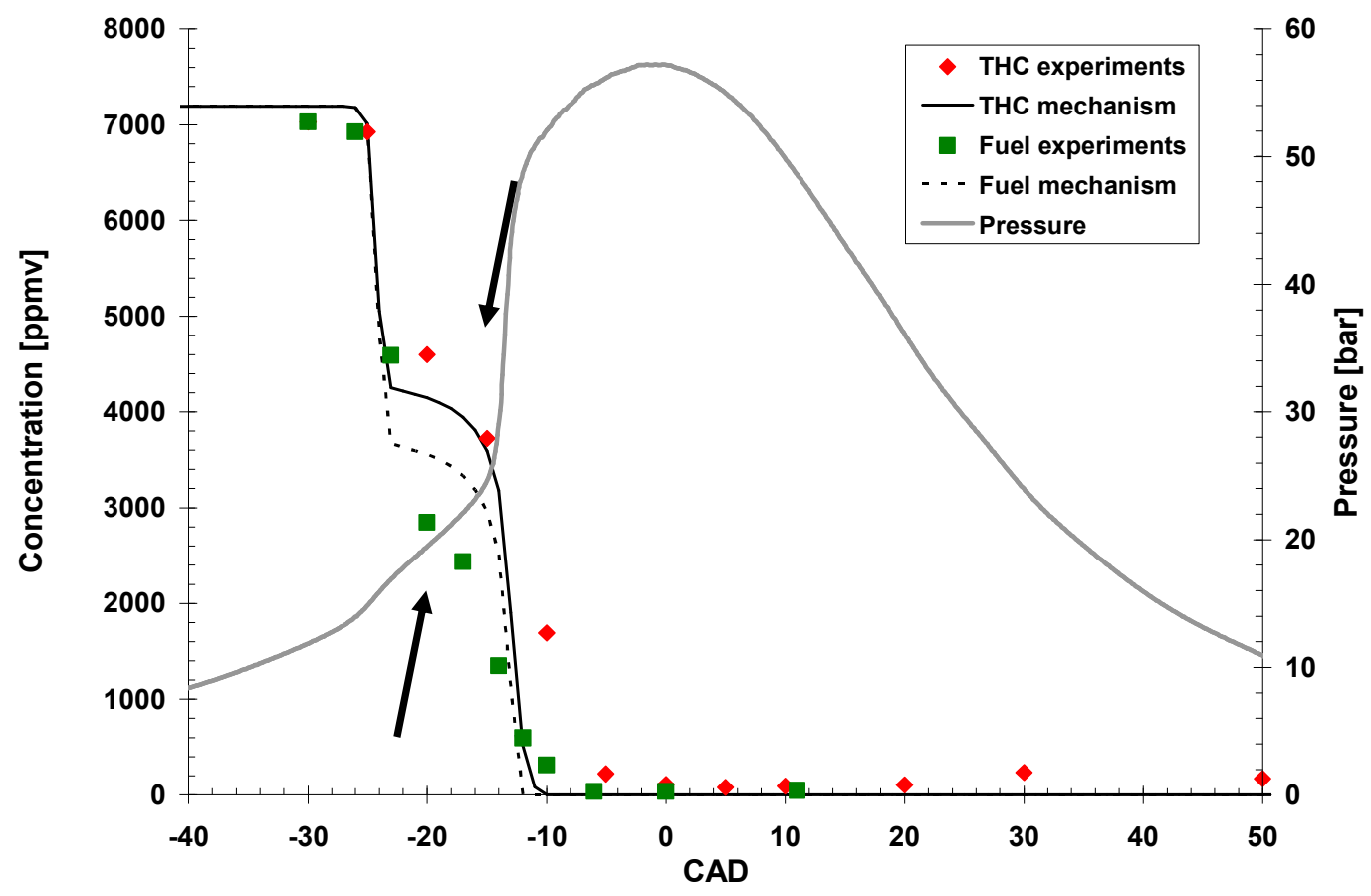

Figure 2: Concentration profile during the combustion of the fuel and the total hydrocarbons; experimental [43] by points and numerical by lines; inlet temperature of $70^{\circ} \mathrm{C}$, equivalence ratio of 0.4, compression ratio of 10.2 and PRF40 as the fuel 


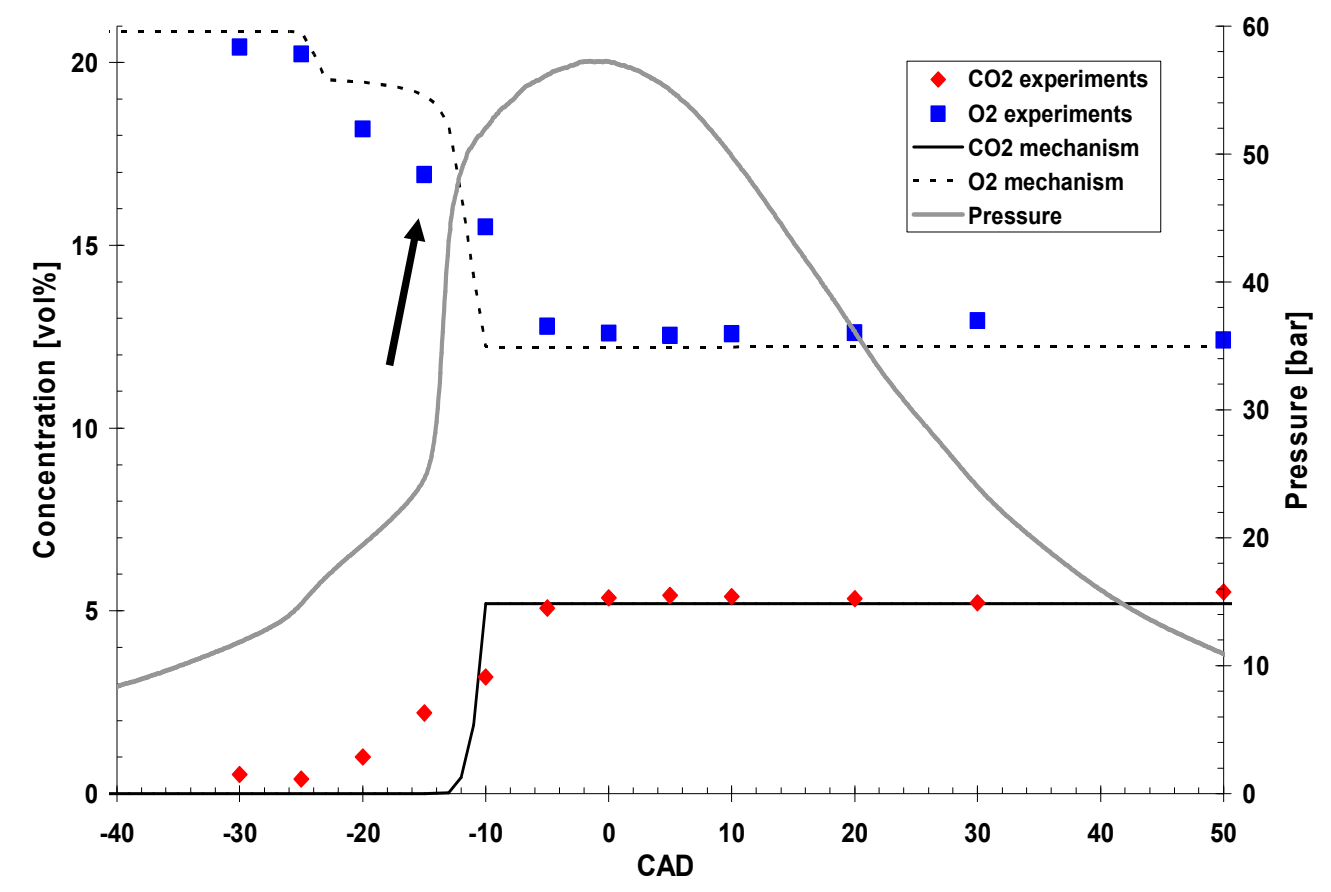

Figure 3: Concentration profile during the combustion of $\mathrm{CO}_{2}$ and $\mathrm{O}_{2}$; experimental [43] by points and numerical by lines; inlet temperature of $70^{\circ} \mathrm{C}$, equivalence ratio of 0.4 , compression ratio of 10.2 and PRF40 as the fuel 


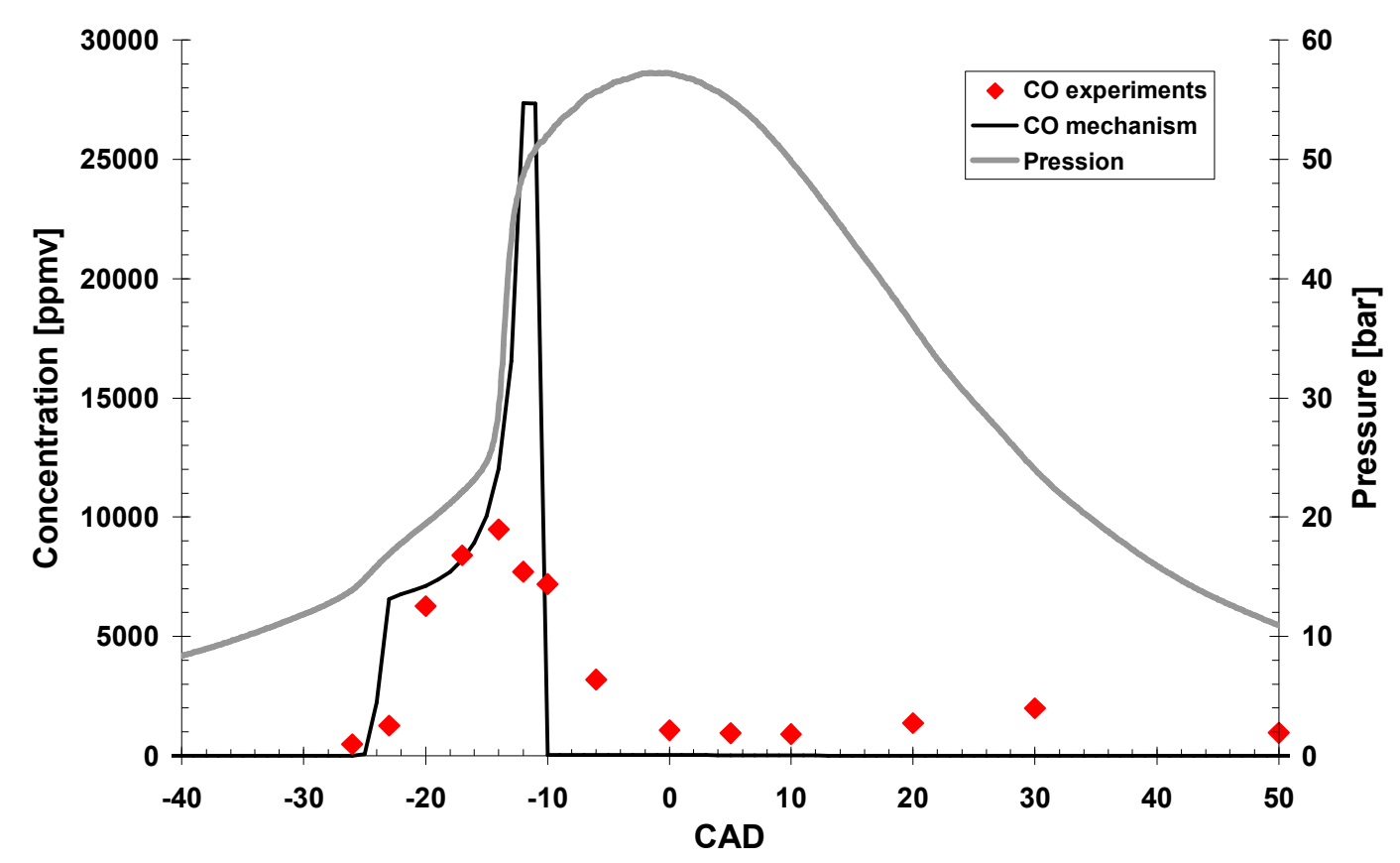

Figure 4: Concentration profile during the combustion of CO; experimental [43] by points and numerical by lines; inlet temperature of $70^{\circ} \mathrm{C}$, equivalence ratio of 0.4 , compression ratio of 10.2 and PRF40 as the fuel 


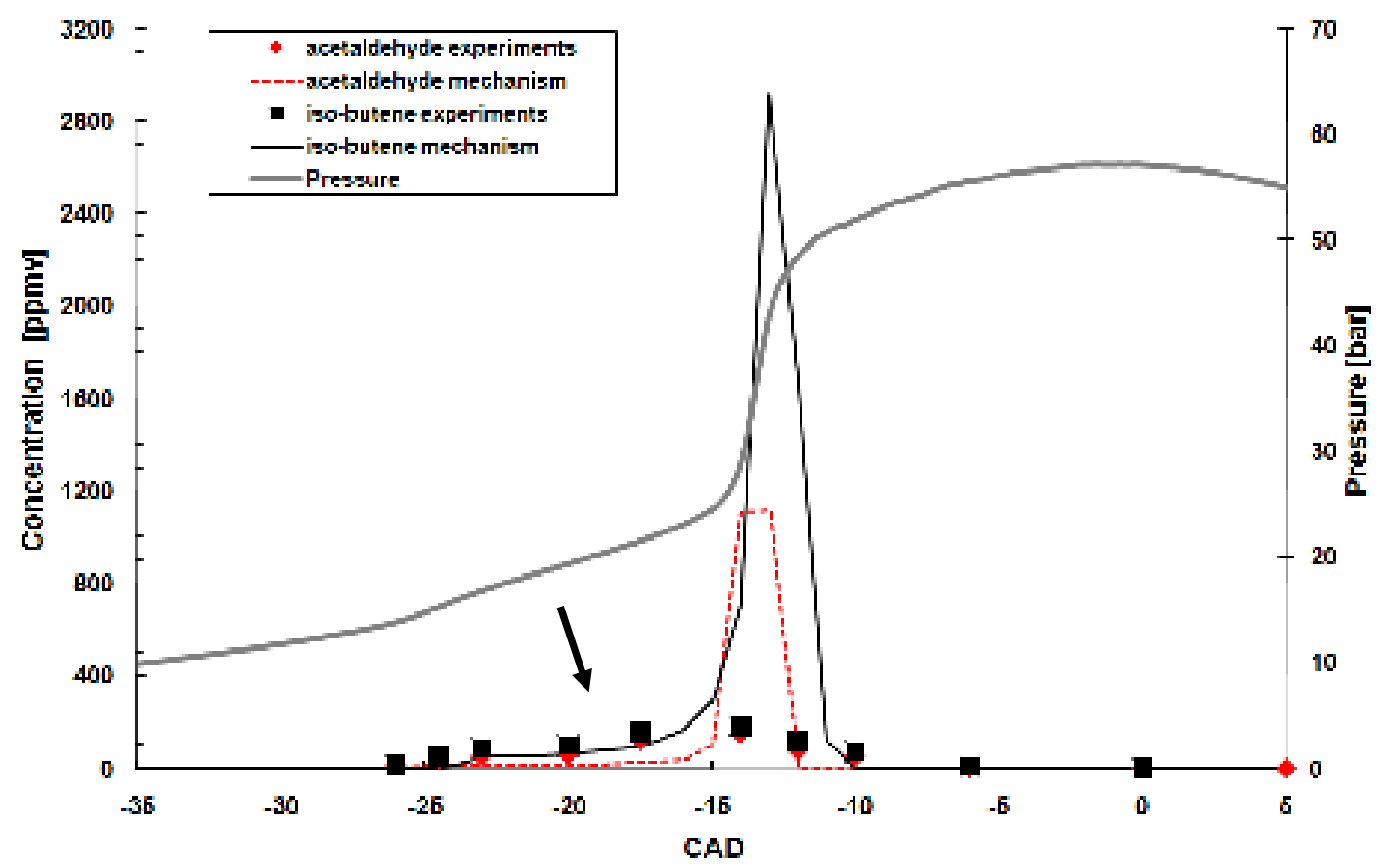

Figure 5: Concentration profile during the combustion of acetaldehyde and iso-butene; experimental [43] by points and numerical by lines; inlet temperature of $70^{\circ} \mathrm{C}$, equivalence ratio of 0.4 , compression ratio of 10.2 and PRF40 as the fuel 


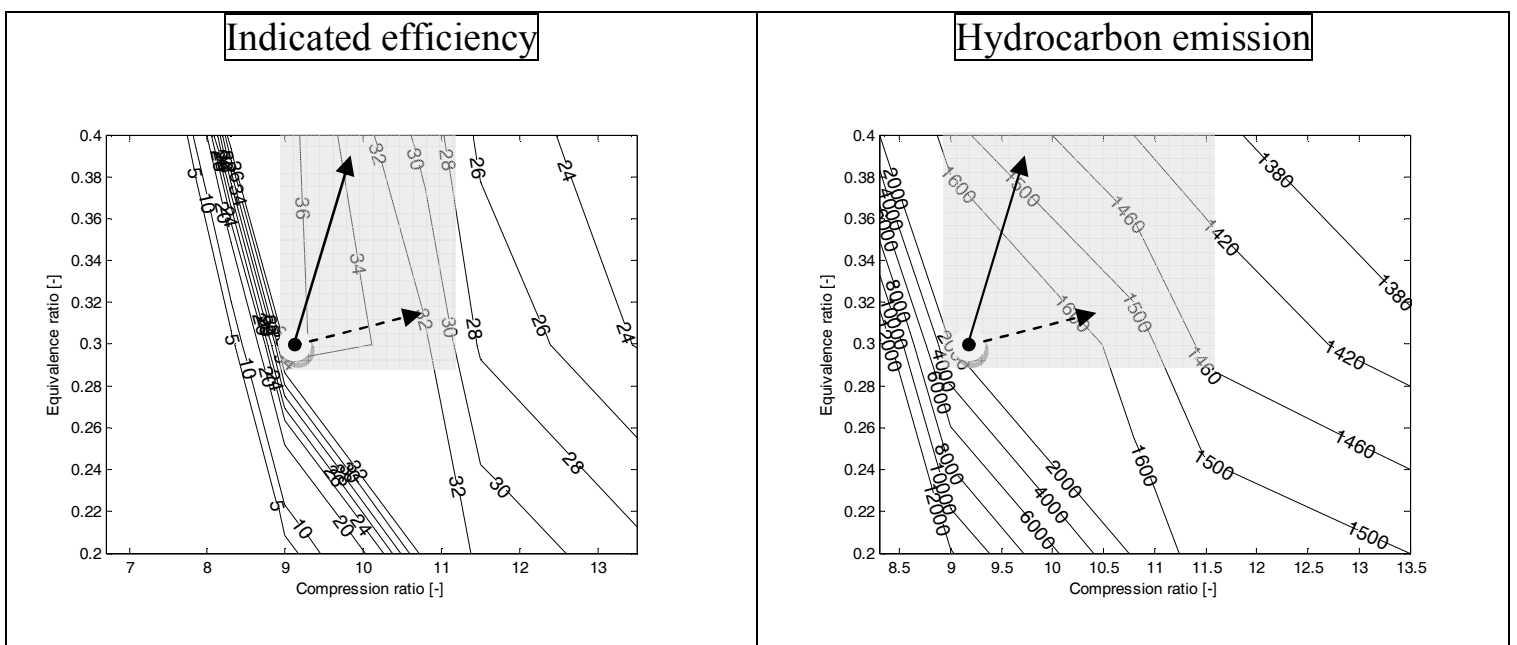

Figure 6: Iso-indicated efficiencies (left in \%), hydrocarbon emissions (right in ppmv) as a function of the equivalence ratio and the compression ratio, for an inlet temperature of $70^{\circ} \mathrm{C}$ with "60 vol\% n-heptane / 40 vol\% iso-octane" as the fuel 


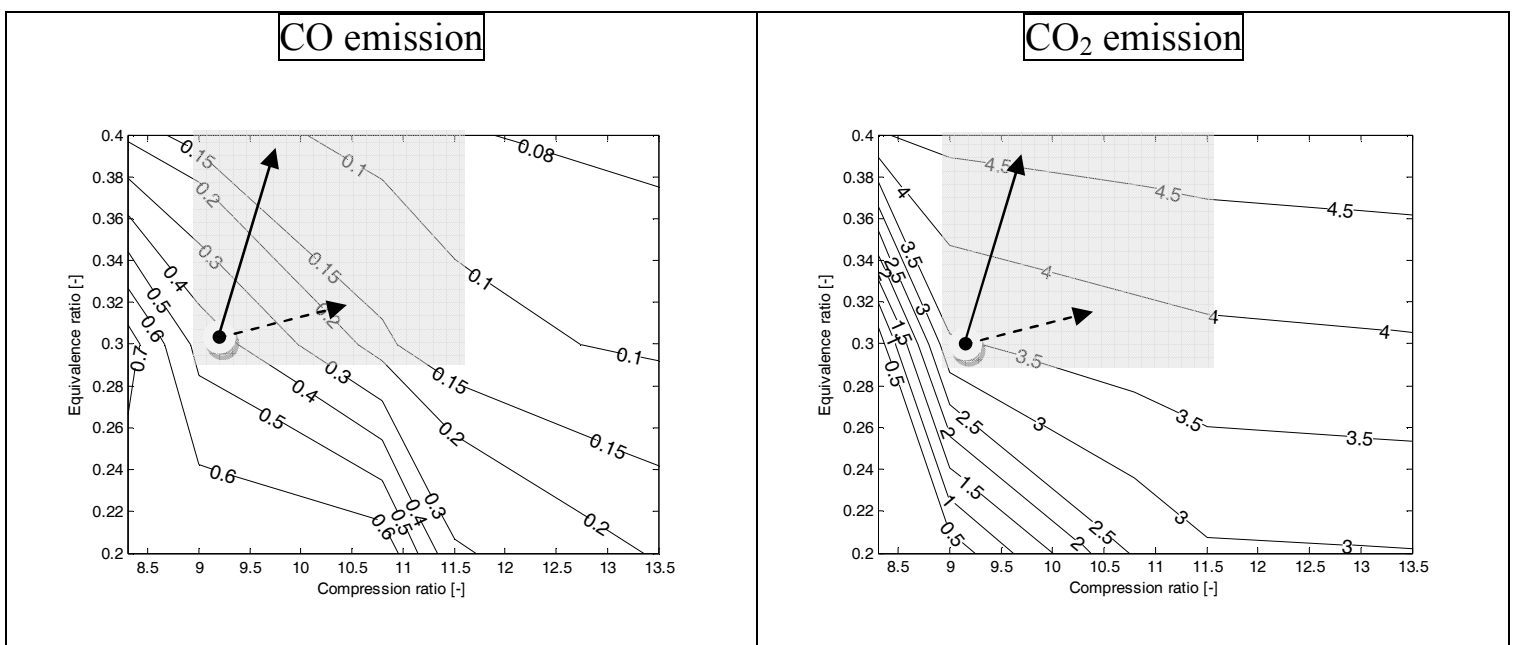

Figure 7: CO emissions (left in vol\%) and $\mathrm{CO}_{2}$ emissions (right in vol\%) as a function of the equivalence ratio and the compression ratio, for an inlet temperature of $70^{\circ} \mathrm{C}$ with " $60 \mathrm{vol} \%$ n-heptane / 40 vol\% iso-octane" as the fuel 


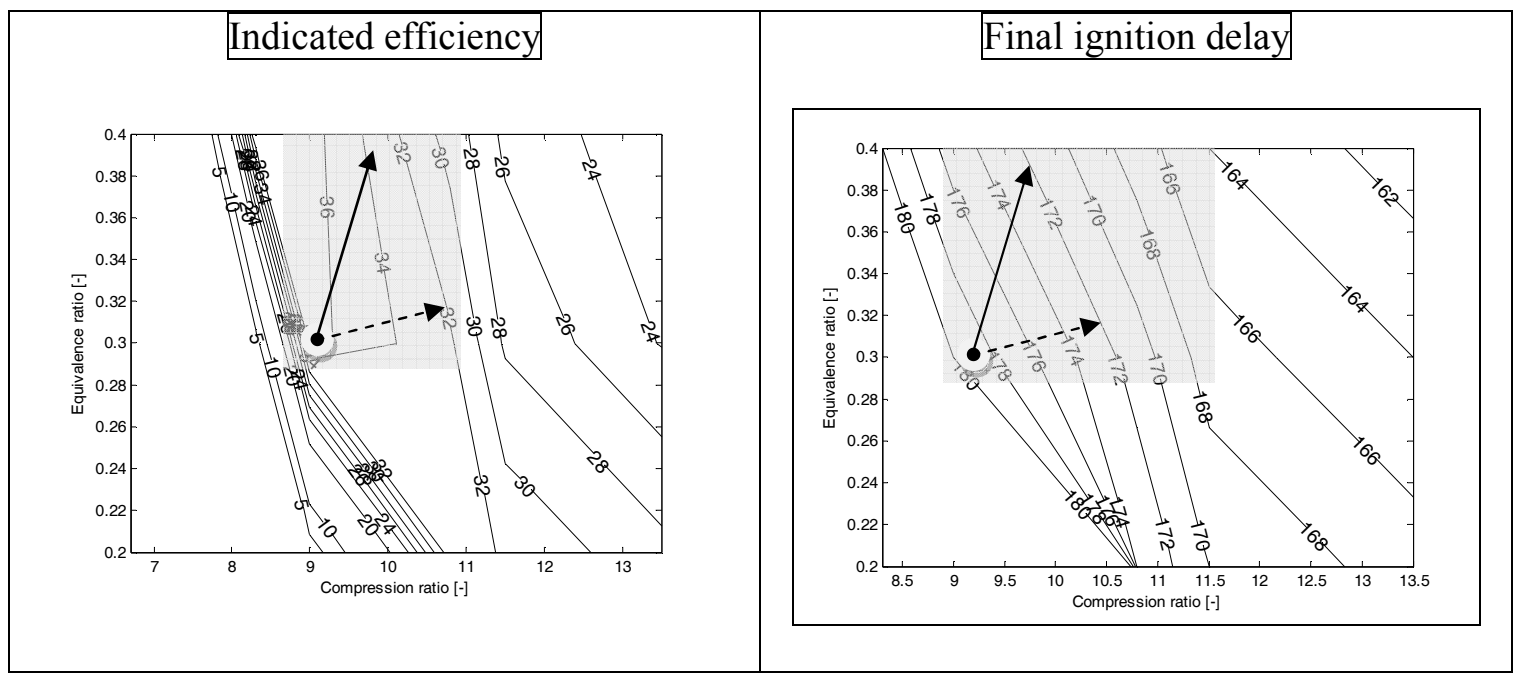

Figure 8: Iso-indicated efficiencies (left in \%) and the final ignition delay (right in CAD) as a function of the equivalence ratio and the compression ratio, for an inlet temperature of $70^{\circ} \mathrm{C}$ with "60 vol\% n-heptane / 40 vol\% iso-octane" as the fuel 